\title{
Two Clostridium perfringens Type E Isolates in France
}

\author{
Laure Diancourt $^{1}$, Jean Sautereau ${ }^{1}$, Alexis Criscuolo ${ }^{2,+}$ (i) and Michel R. Popoff ${ }^{3, *,+}+\mathbb{C}$ \\ 1 CNR Bactéries anaérobies et Botulisme, Institut Pasteur, 75015 Paris, France; \\ laure.diancourt@pasteur.fr (L.D.); jean.sautereau@pasteur.fr (J.S.) \\ 2 Hub de Bioinformatique et Biostatistique-C3BI, Institut Pasteur, USR 3756, CNRS, 75015 Paris, France; \\ alexis.criscuolo@pasteur.fr \\ 3 Bacterial Toxins, Institut Pasteur, ERL 6002, 75015 Paris, France \\ * Correspondence: mpopoff@pasteur.fr \\ + Authors contributed equally to this work.
}

Received: 12 February 2019; Accepted: 23 February 2019; Published: 1 March 2019

\begin{abstract}
Clostridium perfringens type $\mathrm{E}$ is a less frequently isolated C. perfringens type and has not previously been reported in France. We have characterized two recent type $\mathrm{E}$ isolates, $C$. perfringens 508.17 from the intestinal content of a calf that died of enterotoxemia, and 515.17 from the stool of a 60-year-old woman, subsequent to food poisoning, which contained the plasmid PCPPB-1 with variant iota toxin and $C$. perfringens enterotoxin genes.
\end{abstract}

Keywords: Clostridium perfringens; iota toxin; C. perfringens enterotoxin; enterotoxemia; food poisoning

Key Contribution: The first two Clostridium perfringens type E isolates in France have been characterized by whole genome sequencing and iota toxin activity. These strains also contain alpha toxin, perfringolysin, and variant cpe genes.

\section{Introduction}

Clostridium perfringens is a ubiquitous gram-positive, spore forming anaerobic bacterium which produces different toxins and is responsible for various diseases in man and animals such as gangrene, food poisoning, diarrhea, necrotic enteritis, and enterotoxemia. Based on the production of four toxins (alpha, beta, epsilon, and iota), C. perfringens was traditionally divided into five toxin types (A to E) [1]. More recently, the C. perfringens nomenclature was expanded to seven types (A to $G$ ) by adding C. perfringens enterotoxin (CPE) and NetB carrying strains as different toxin types [2].

C. perfringens type $\mathrm{E}$ is characterized by the production of iota toxin. Iota toxin is a binary toxin consisting of a binding component $(\mathrm{Ib})$ and an enzymatic component (Ia) which enters cells and modifies the actin cytoskeleton by ADP-ribosylation of actin monomers [3,4]. C. perfringens type $\mathrm{E}$ is a less frequently isolated type from clinical samples. This toxin type has been isolated from cases of diarrhea or hemorrhagic enteritis and sudden death in neonatal calves, mainly in the US, and more rarely in other animals such as chickens, lambs, goats, and cows [5-13]. In France, C. perfringens type $\mathrm{E}$ isolation has not been previously reported. Here we describe two recent type $\mathrm{E}$ isolates, 508.17 and 515.17.

\section{Results}

\subsection{Identification of Two C. perfringens Type E and Investigation of Iota Toxin Production}

The two C. perfringens isolates 508.17 and 515.17 were identified as C. perfringens type E by detection of iota toxin genes with routine PCR toxin gene identification of $C$. perfringens [14]. 
The production of iota toxin in C. perfringens 508.17 and 515.17 was investigated by western blotting with specific antibodies against $\mathrm{Ia}$ and $\mathrm{Ib}$. The reference type A C. perfringens strain ATCC 13124 was used as a control. As shown in Figure 1, both components Ia and Ib were detected in the supernatant of C. perfringens 508.17 and 515.17 but not in C. perfringens ATCC 13124.

The biological activity was tested on Vero cells. The concentration of culture supernatant yielding $50 \%$ rounded cells was $156 \mathrm{ng} / \mathrm{mL}$ (total protein) for 508.17 and $650 \mathrm{ng} / \mathrm{mL}$ (total protein) for 515.17. The level of cytotoxicity was increased four-fold after $\alpha$-chymotrypsin treatment of the culture supernatants. In comparison, the $50 \%$ cytotoxic activity of purified recombinant iota toxin on Vero cells was obtained with $15 \mathrm{ng} / \mathrm{mL} \mathrm{Ib}$ and $8 \mathrm{ng} / \mathrm{mL}$ Ia (not shown).

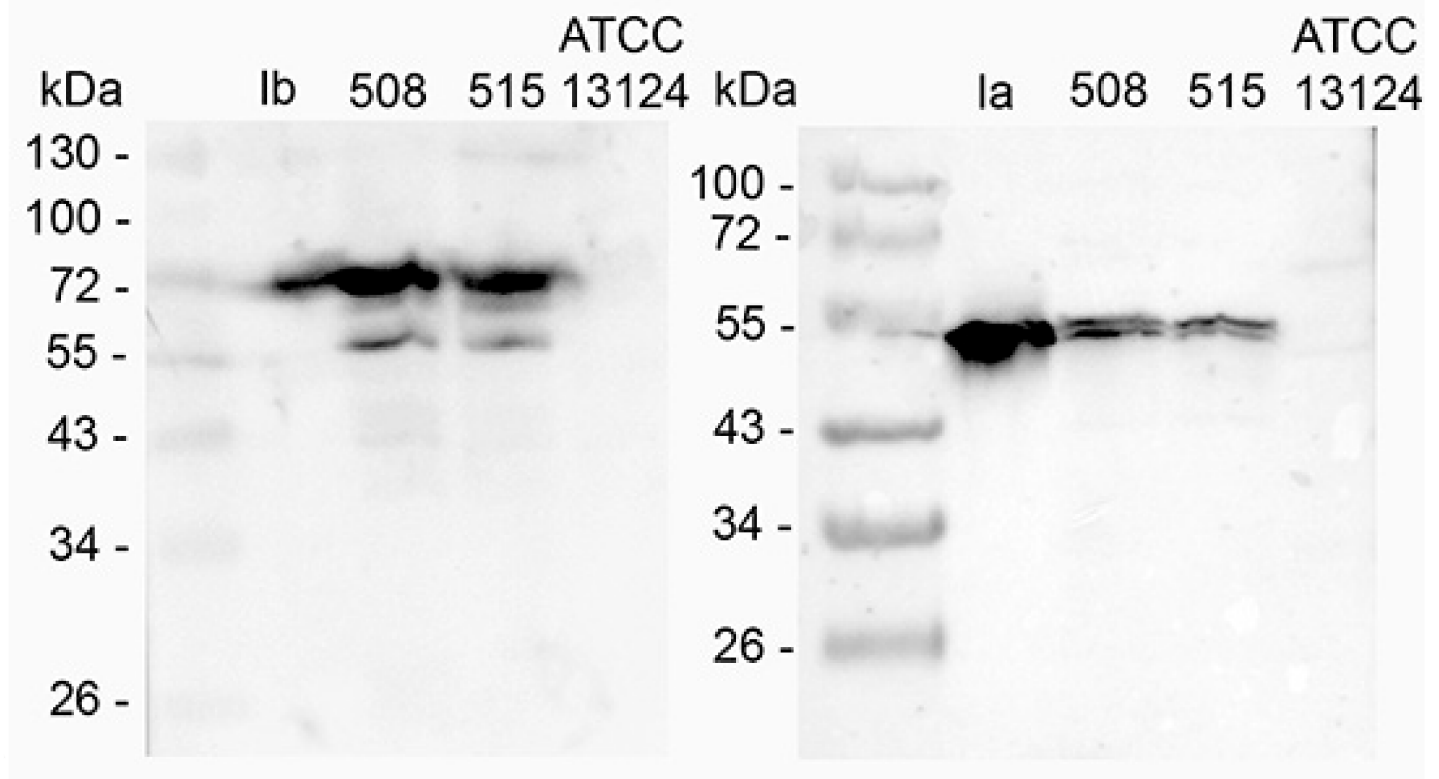

Figure 1. Production of iota toxin in C. perfringens 508.17 (508), 515.17 (515), and ATCC 13124.

Concentrated supernatants of C. perfringens 508.17 (5 $\mu \mathrm{g}$ total protein), C. perfringens 515.17 (5 $\mu \mathrm{g}$ total protein), and C. perfringens ATCC 13124 (5 $\mu \mathrm{g}$ total protein) as control, as well as purified Ia (1 ng) and $\mathrm{Ib}(1 \mathrm{ng})$ were run on a 10\% SDS-PAGE and transferred on nitrocellulose. Blots were incubated with specific rabbit serum against $\mathrm{Ia}$ and $\mathrm{Ib}$, respectively, and then with goat immunoglobulin against rabbit IgG labeled with peroxidase. The bands at $55 \mathrm{kDa}$ in the western blot with anti-Ib and the double bands in the western blot with anti-Ia resulted from partial proteolytic degradation.

\subsection{In Vitro Actin ADP-Ribosylation}

The enzymatic activity of iota toxin in C. perfringens 508.17 and 515.17 culture supernatants was tested by in vitro ADP-ribosylation with muscular and cellular actin. As shown in Figure 2, ADP-ribosylation of both muscular and cellular actin was observed with culture supernatants from C. perfringens 508.17 and 515.17, as well as the purified Ia control. The type A C. perfringens ATCC 13124 did not show any actin ADP-ribosylation. 


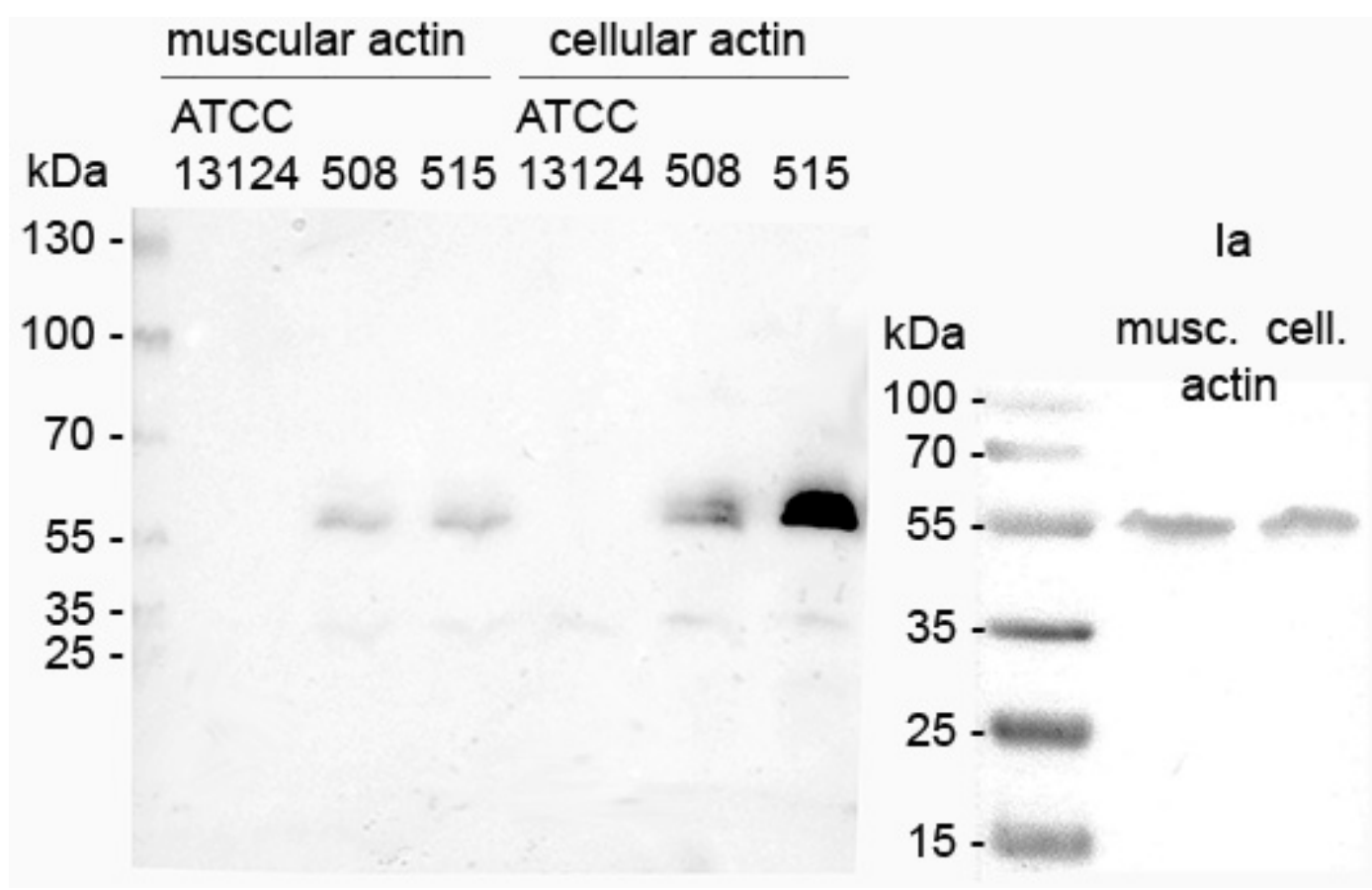

Figure 2. In vitro ADP-ribosylation of muscular and cellular actin with C. perfringens 508.17 (508) and 515.17 (515). ADP-ribosylation with purified Ia from NCIB10748 is shown as a positive control. No actin ADP-ribosylation was observed with the type A C. perfringens strain ATCC 13124.

\subsection{Whole Genome Sequencing}

The two de novo assemblies are quite similar at first sight, i.e., 3.47 and $3.58 \mathrm{Mbs}, 28.00 \%$ and $28.06 \%$ GC-content, 3,085 and 3,286 CDS for isolates 508.17 and 515.17, respectively. However, scaffolds from isolate 508.17 contain only one sequence that is almost identical to pCPPB-1 (accession number UWOV01000018; 99.8\% similarity), whereas those from isolate 515.17 contain 19 sequences that could be reordered against pCPPB-1 (i.e., UWOU0100067, 108, 087, 023, 106, 043, 047, 005, 018, 003, 036, 090, 086, 068, 013, 006, 014, 007, 101; 99.7\% identity), and 7 additional sequences showing strong BLAST similarity (e.g., >99.7\% identity) with pJFP838D and pD13118_cpe (i.e., UWOU0100008, 009, $016,022,024,026,034)$. This indicates that the strain 515.17 contains two additional plasmids related to pJFP838D and pD13118_cpe, or a plasmid combining these sequences.

Iota toxin Ia and $\mathrm{Ib}$ components from 508.17 and 515.17 strains are highly similar $(99.73 \%$ and $99.83 \%$ at the amino acid level), closely similar to those of pCPPB- 1 iota toxin components $(99.87 \%$ similarity), and more distantly related to classical iota toxin (91.2\% and $89.7 \%$, respectively) (Table 1$)$. Iota toxin sequences from 508.17 and 515.17 strains show a low relatedness (40-42\% identity) to iota toxin variant BEC/CPILE found in contaminated food in Japan $[15,16]$. 
Table 1. Amino acid (aa) sequence comparison of iota toxin components Ia and $\mathrm{Ib}$ from 508.17 and 515.17 strains versus classical iota toxin (X73562) from NCIB10748 and iota variant from pCPPB-1.

\begin{tabular}{ccccccccc}
\hline \multirow{2}{*}{ Strain/Sequence } & \multicolumn{3}{c}{ Iota Ia Similarity \% (aa) } & \multicolumn{5}{c}{ Iota Ib Similarity \% (aa) } \\
\cline { 2 - 9 } & $\mathbf{5 0 8 . 1 7}$ & pCPPB-1 & $\mathbf{5 1 5 . 1 7}$ & $\mathbf{X 7 3 5 6 2}$ & $\mathbf{5 0 8 . 1 7}$ & pCPPB-1 & $\mathbf{5 1 5 . 1 7}$ & X73562 \\
\hline 508.17 & 100.00 & & & 100.00 & & \\
\hline pCPPB-1 & 99.87 & 100.00 & & 99.85 & 100.00 & \\
\hline 515.17 & 99.73 & 99.86 & 100.00 & 99.93 & 99.86 & 100.00 \\
\hline X73562 & 91.20 & 91.33 & 91.19 & 100.00 & 89.69 & 89.77 & 89.77 & 100.00 \\
\hline
\end{tabular}

The two isolates also contain alpha toxin, perfringolysin, and cpe genes. CPE from 508.17 and 515.17 strains are identical at the amino acid sequence level with variant $C P E$ from $\mathrm{PCPPB}-1$, and differ from classical CPE at 12 positions (Table 2).

Table 2. Comparative alignment and amino acid similarity of CPE 508.17 and 515.17 versus pCPPB-1 variant CPE as well as pCPF4969 and pJFP838-all classical plasmid CPE. The amino acid (aa) changes between variant and classical CPE are indicated. CPE sequences from 508.17 and 515.17 match with that of $\mathrm{PCPPB}-1$ and diverge at 12 positions from classical CPE.

\begin{tabular}{|c|c|c|c|c|c|c|c|c|c|c|c|c|c|c|c|c|}
\hline \multirow{2}{*}{ Strain/Sequence } & \multicolumn{12}{|c|}{ Variable aa Positions on cpe } & \multicolumn{4}{|c|}{ Similarity \% } \\
\hline & 18 & 20 & 32 & 172 & 193 & 217 & 257 & 275 & 276 & 283 & 287 & 313 & 508.17 & 515.17 & рСРРВ-1 & pCPF4969 \\
\hline 508.17 & $\mathrm{~L}$ & $\mathrm{~V}$ & K & A & S & $\mathrm{T}$ & $\mathrm{R}$ & Q & $\mathrm{E}$ & $\mathrm{N}$ & I & A & - & & & \\
\hline 515.17 & $\mathrm{~L}$ & $\mathrm{~V}$ & K & A & $S$ & $\mathrm{~T}$ & $\mathrm{R}$ & Q & $\mathrm{E}$ & $\mathrm{N}$ & I & A & 99.07 & - & & \\
\hline pCPPB-1 & $\mathrm{L}$ & $\mathrm{V}$ & $\mathrm{K}$ & A & S & $\mathrm{T}$ & $\mathrm{R}$ & Q & $\mathrm{E}$ & $\mathrm{N}$ & I & A & 100.00 & 99.07 & - & \\
\hline pCPF4969 & $\mathrm{F}$ & I & $\mathrm{N}$ & G & $\mathrm{T}$ & $S$ & K & $\mathrm{E}$ & Q & $\mathrm{K}$ & $\mathrm{V}$ & $S$ & 96.36 & 97.3 & 96.36 & - \\
\hline pJFP838-all & $\mathrm{F}$ & I & $\mathrm{N}$ & $G$ & $\mathrm{~T}$ & $S$ & $\mathrm{~K}$ & $E$ & $Q$ & $\mathrm{~K}$ & $\mathrm{~V}$ & $\mathrm{~S}$ & 96.36 & 97.3 & 96.36 & 100.00 \\
\hline
\end{tabular}

\subsection{Phylogenetic Analysis}

Phylogenetic analysis of the C. perfringens core-genome shows that the two strains 508.17 and 515.17 are related but not identical (Figure 3). Both strains are neighbors within a specific clade, emerging between the type A strain MJR7757A (originated from a human host) and type A JFP strains (originated from foal or dog hosts). However, they are distantly related to the classical C. perfringens type E strain JGS1987. Of note, the strain 508.17 is characterized by the absence of the toxin gene $c p b 2$, whereas the two type E strains 515.17 and JGS1987 show identical toxin gene content. 


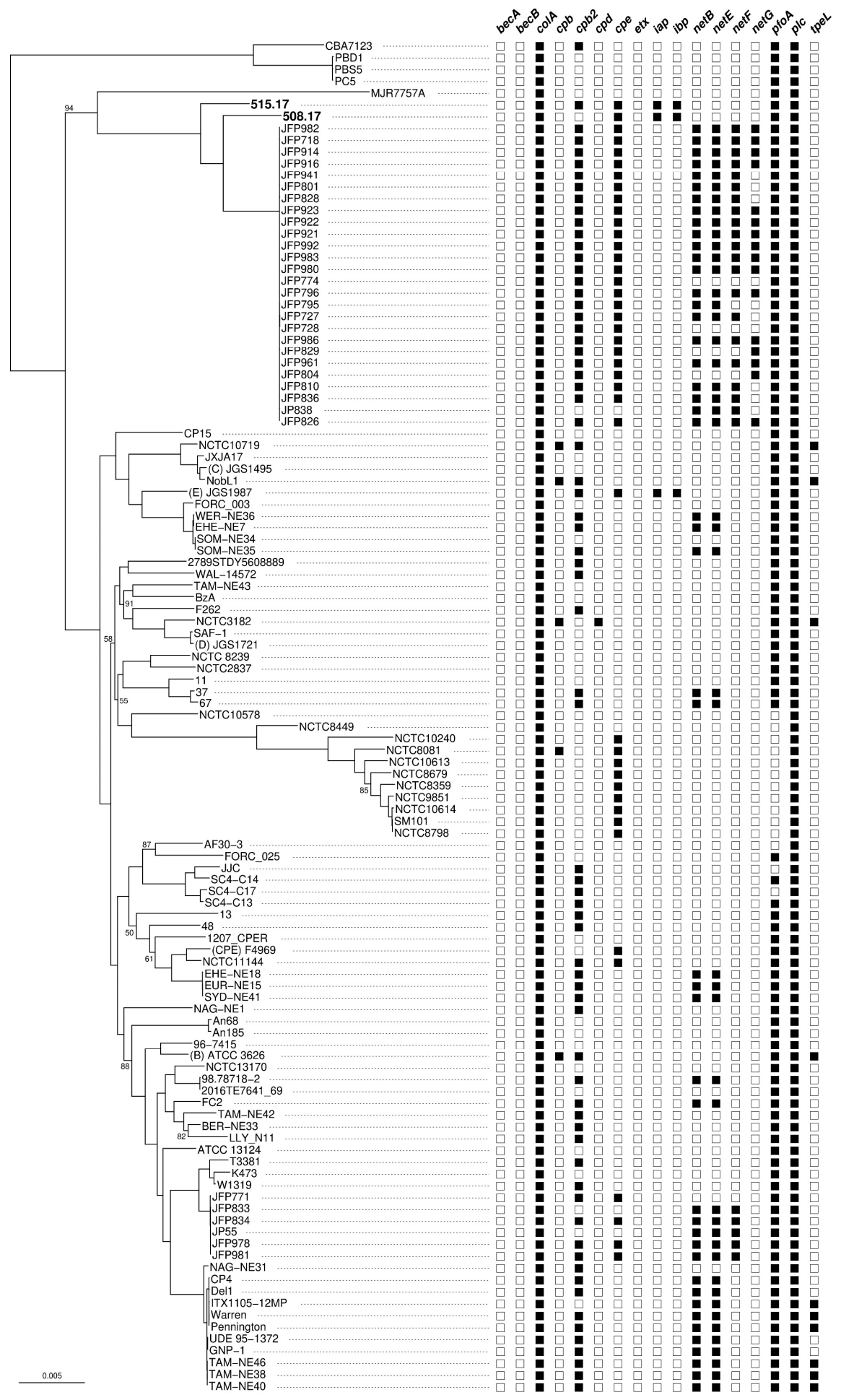

Figure 3. Maximum likelihood phylogenetic tree of $C$. perfringens based on their core genome and presence/absence pattern of 17 toxin genes. Each branch support was assessed by the ultrafast bootstrap approach (only support values $<95 \%$ are shown). The scale bar represents 0.005 substitutions per nucleotide. The presence/absence of each of the 17 toxin genes is indicated by a black/white square for each of the 115 analyzed genomes. becAB: binary enterotoxin of $C$. perfringens; colA: collagenase A; $c p b$ : C. perfringens beta toxin; $c p b 2, c p d$ : C. perfringens delta toxins; cpe: C. perfringens enterotoxin; etx: C. perfringens epsilon toxin; iap, ibp: C. perfringens iota toxin; netBEFG: necrotic enteritis toxins; $p f_{0} A$ : perfringolysin; plc: C. perfringens alpha toxin; tpeL: toxin perfringens large cytotoxin. 


\section{Discussion}

Most C. perfringens type E strains have been found to contain the iota toxin (iap and ibp) genes on a plasmid flanked by the insertion sequence IS1151 and in close proximity to a silent cpe gene [17]. Iota toxin plasmids have mostly a pCPF5603 backbone with insertion of iap and ibp genes within the cpe promoter, thus preventing cpe transcription in addition to nonsense and frame-shift mutations in the open reading frame (ORF) [13]. More recently, four C. perfringens type E strains have been characterized to have iap and ibp genes on a pCPPB-1-related plasmid. pCPPB- 1 is a $\sim 67 \mathrm{kbp}$ plasmid containing 72 putative ORFs that are organized in three regions, a putative replication plasmid and transfer region, a toxin region, and a variable region. pCPPB- 1 retains the backbone of pCPF4969 that is the classical plasmid containing cpe in C. perfringens type A, but lacks IS elements in the vicinity of toxin genes. In contrast to PCPF5603, pCPPB-1 contains a functional cpe. Indeed, albeit iap and ibp genes are inserted into the cpe promoter region, only the promoter $\mathrm{P} 3$ is missing. The two other cpe promoters (P1 and P2) are the major promoters, and are preserved, therefore allowing cpe expression. This is in contrast to the strains with iota toxin plasmid of the pCPF5603 family, which produce no CPE even in sporulation conditions [18]. Iota and cpe genes harbored on PCPPB-1 plasmid show variations with the corresponding genes on classical strains. Indeed, iap and ibp from pCPPB- 1 share $87 \%$ and $89 \%$ identity with the corresponding genes of C. perfringens E NCIB10748 $[18,19]$, respectively, at the nucleotide level. The variant CPE from pCPPB-1 is $96 \%$ identical (10 amino acid differences on 319) to classical CPE [18].

Recently, C. perfringens strains isolated from food poisoning outbreaks in Japan were characterized as producing an iota toxin variant called BEC (binary toxin of C. perfringens) or CPILE (Clostridium perfringens iota-like enterotoxin) $[15,16]$. These strains lack cpe genes and CPE production. The two components BECa/CPILE-a and BECb/CPILE-b share $43 \%$ and $41-42 \%$ identity with Ia and Ib from the classical C. perfringens type E strain NCIB10748, respectively $[15,16]$. bec $A$ and becB are located on a large size plasmid (pCP-OS1/pCP-TS1, 54,635 bp) for which most parts (69\%) are highly similar (92-99\% identity) with sequences of the plasmid pCP13 from C. perfringens strain 13 [18]. BEC/CPILE is enterotoxic and induces fluid accumulation in rabbit ileal loop and suckling mice $[15,18]$. BECa/CPILEa ADP-ribosylates all isoforms of actin monomers and retains a similar structure compared to Ia [20]. Iota toxins from strains 508.17 and 515.17 share the same enzymatic activity profile as BEC/CPILE. Indeed, they also ADP-ribosylate both muscular and cellular actin. However, iota toxins from 508.17 and 515.17 as well as the classical iota toxin retain a low level of identity with BEC/CPILE.

The two French C. perfringens type E isolates have distinct chromosomal genetic backgrounds related but not identical to those of the variant $C$. perfringens type E [18]. They are distantly related to the classical C. perfringens type $\mathrm{E}$ and enterotoxigenic and non-enterotoxigenic type A strains, as well as type A strains with chromosomally located cpe [21,22] (Figure 3). However, the two French isolates have acquired a pCPPB-1 plasmid similar to that found in the variant $C$. perfringens type $E$ strains isolated from meat products in Japan [18]. The two French isolates 508.17 and 515.17 have distinct origins, from calf and food intoxication in man, respectively. Their relatedness with C. perfringens type E strains reported in Japan raises questions as to whether they share a common source, and what the possible mode of dissemination might be.

\section{Materials and Methods}

\subsection{C. perfringens Isolates}

C. perfringens 508.17 was isolated from the intestinal content of a 6-month-old calf that died with an enterotoxemia syndrome in central France. The calf received a vaccination against blue tongue one day before. The strain 515.17 was from the stool of a 60 -year-old woman in a nursing home showing a C. perfringens food poisoning. The stool of two other patients of the same food poisoning outbreak yielded classical enterotoxigenic $C$. perfringens strains with cpe gene located on the chromosome. 


\subsection{C. perfringens Cultures}

C. perfringens strains were grown in trypticase-glucose-yeast extract ( $20 \mathrm{~g}$ of Trypticase, $30 \mathrm{~g}$ of yeast extract, and $0.5 \mathrm{~g}$ of cysteine hydrochloride per liter, pH 7.2) (TGY) [23] under anaerobic conditions at $37^{\circ} \mathrm{C}$ overnight. The culture supernatant was concentrated (about 20-fold) by ammonium sulfate precipitation (70\% saturation), centrifuged at 10,000 rpm for $10 \mathrm{~min}$, and then dialysis against Tris-HCl 10 mM, pH 7.5. Protein concentration was determined by the Bradford method [24].

\subsection{Iota Toxin Production and Purification}

Ia and $\mathrm{Ib}$ components of iota toxin were produced and purified as previously described [23]. Briefly, iap and ibp from C. perfringens NCIB10748 were cloned into the Escherichia coli-C. perfringens shuttle vector pJIR750 yielding pMRP147 and pMRP384 which have been transfected by electroporation into the lecithinase-negative $C$. perfringens strain 667. The recombinant $C$. perfringens strains were grown and the culture supernatants were processed as indicated above. Ia and Ib were purified by DEAE-Sephacel chromatography and gel filtration on Superdex200 as previously described [23].

Rabbit antibodies against purified $\mathrm{Ia}$ and $\mathrm{Ib}$ were produced and checked as previously described $[25,26]$.

\subsection{Western Blotting}

C. perfringens concentrated culture supernatants Ia and $\mathrm{Ib}$ were run on a 10\% SDS-PAGE and transferred onto nitrocellulose. After blocking with 5\% nonfat dry milk in phosphate-buffered saline, the membranes were washed with Tris- $\mathrm{HCl} 10 \mathrm{mM}$ ( $\mathrm{pH} 7.5$ ) containing $150 \mathrm{mM} \mathrm{NaCl}$ and $0.1 \%$ Tween20 (TTS). The membranes were incubated with either rabbit anti-Ia or anti-Ib antibodies (1:3000 concentration) (Jackson Immunoresearch 111-035-006) for $1 \mathrm{~h}$ at room temperature. After three washes in TTS, membranes were incubated with horseradish peroxidase goat anti-rabbit immunoglobulins (1:3000) for $1 \mathrm{~h}$ at room temperature, and then processed for chemiluminescence with Immobilon Western (Millipore, Guyancourt 78280, France).

\subsection{ADP-Ribosylation}

For ADP-ribosylation, the following buffer was used: Tris $50 \mathrm{mM}$ (pH 7.5) containing $5 \mathrm{mM} \mathrm{MgCl}$, $10 \mathrm{mM}$ dithiothreitol, $10 \mathrm{mM}$ thymidine, protease inhibitors (leupeptine $0.1 \mathrm{mM}$, pepstatin $1 \mathrm{mM}$, PMSF $2 \mathrm{mM}$ ), and biotin-NAD (Trevigen 4670-500-01) $12 \mu \mathrm{M}$. In vitro ADP-ribosylation was performed in $20 \mu \mathrm{l}$ of the above buffer containing either $1 \mu \mathrm{g}$ muscular (Sigma A-3653) or cellular (Cytoskeleton APHL95) actin, and $1 \mu \mathrm{L}$ of concentrated C. perfringens culture supernatant. After $1 \mathrm{~h}$ incubation at $37^{\circ} \mathrm{C}$, the samples were run in SDS-PAGE, transferred onto nitrocellulose, processed with peroxidase streptavidin conjugate (Roche 11-089-153-001) 1:3000 for $1 \mathrm{~h}$, and processed for chemiluminescence as in Section 4.4 .

\subsection{Cytotoxicity Assay}

Vero (African green monkey kidney) cells were grown in Dulbecco's modified Eagle medium (DMEM) supplemented with $10 \%$ fetal calf serum at $37^{\circ} \mathrm{C}$ and $5 \% \mathrm{CO}_{2}$. Cells were grown as confluent monolayers in 96-well plates. Then, the medium was changed to DMEM containing $0.1 \%$ bovine serum albumin and the cells were incubated with serial dilutions of $C$. perfringens culture supernatants. Changes in cell morphology characterized by cell rounding were microscopically observed after $18 \mathrm{~h}$ incubation.

\subsection{Genome Sequencing, Assembly, and Analysis}

Genomic DNA from C. perfringens strains was extracted and purified as previously described [27]. Whole-genome shotgun sequencing was performed using an Illumina NextSeq 500 sequencer. Libraries were constructed using Nextera XT technology and sequenced using a $2 \times 150$ nucleotide paired-end 
strategy. All reads were preprocessed to remove or correct artefactual or low quality bases. Sequenced reads were assembled using SPAdes (v. 3.11.0, St. Petersburg State University, St. Petersburg, Russian Federation, 2017) [28], and resulting scaffold sequences were annotated using Prokka (v. 1.11, University of Melbourne, Melbourne, Australia, 2014) [29]. Specific toxin genes (i.e., becAB, colA, $c p b$, $c p b 2, c p d, c p e, e t x$, iap, ibp, netBEFG, pfo $A, p l c, t p e L)$ were searched against genome sequences using BioNumerics (v. 7.6, Applied Maths NV, www.applied-maths.com, Sint-Martens-Latem, Belgium, 2016). In order to identify plasmid sequences within each assembly, the scaffold sequences were reordered against the complete chromosome of C. perfringens ATCC 13124 using Contiguator (v. 2.7.4, University of Florence, Florence, Italy, 2014) [30,31], and each non-ordered sequences was used as query to perform a BLAST search against all publicly available $C$. perfringens plasmid sequences (selection criteria: $90 \%$ similarity and $70 \%$ query coverage).

\subsection{Phylogenetic Reconstruction}

All publicly available $C$. perfringens genome assemblies were gathered from the NCBI repository (www.ncbi.nlm.nih.gov/genome/genomes/158) in order to build a recombination-purged core-genome using Parsnp (v. 1.1.2, National Biodefense Analysis and Countermeasures Center, Frederick, MD, USA, 2014) [32]. The resulting 1,211,302 aligned core nucleotide characters were analyzed using IQ-TREE (v. 1.6.7.2, University of Vienna, Wien, Austria, 2018) [33] to infer a maximum likelihood phylogenetic tree on 115 taxa with the evolutionary model GTR+F+R10 (automatically selected by IQ-TREE from the data).

\subsection{Sequence Accession}

The assembled genome sequences of strains 508.17 and 515.17 were deposited in the European Nucleotide Archive and are available under accession numbers UWOV01000001-UWOV01000120 and UWOU01000001-UWOU01000116, respectively.

Author Contributions: Conceptualization, M.R.P. and A.C.; Methodology, L.D., J.S., and M.R.P.; Software, A.C. and L.D.; Writing M.R.P., A.C. and L.D.

Funding: This research received no external funding.

Acknowledgments: We thank the Mutualized Platform of Microbiology (P2M) of Institut Pasteur for genome sequencing.

Conflicts of Interest: The authors declare no conflict of interest.

\section{References}

1. Petit, L.; Gibert, M.; Popoff, M.R. Clostridium perfringens: Toxinotype and genotype. Trends Microbiol. 1999, 7, 104-110. [CrossRef]

2. Rood, J.I.; Adams, V.; Lacey, J.; Lyras, D.; McClane, B.A.; Melville, S.B.; Moore, R.J.; Popoff, M.R.; Sarker, M.R.; Songer, J.G.; et al. Expansion of the Clostridium perfringens toxin-based typing scheme. Anaerobe 2018, 53, 5-10. [CrossRef] [PubMed]

3. Stiles, B.G.; Pradhan, K.; Fleming, J.M.; Samy, R.P.; Barth, H.; Popoff, M.R. Clostridium and Bacillus binary enterotoxins: Bad for the bowels, and eukaryotic being. Toxins 2014, 6, 2626-2656. [CrossRef] [PubMed]

4. Barth, H.; Aktories, K.; Popoff, M.R.; Stiles, B.G. Binary bacterial toxins: Biochemistry, biology, and applications of common Clostridium and Bacillus proteins. Microbiol. Mol. Biol. Rev. 2004, 68, 373-402. [CrossRef] [PubMed]

5. Songer, J.G. Clostridial diseases in domestic animals. In Handbook on Clostridia; Dürre, P., Ed.; CRC Press, Taylor and Francis Group: Boca Raton, FL, USA, 2005; pp. 527-542.

6. Songer, J.G.; Miskimmins, D.W. Clostridium perfringens type E enteritis in calves: Two cases and a brief review of the literature. Anaerobe 2004, 10, 239-242. [CrossRef] [PubMed]

7. Uzal, F.A.; Songer, J.G. Diagnosis of Clostridium perfringens intestinal infections in sheep and goats. J. Vet. Diagn. Investig. 2008, 20, 253-265. [CrossRef] [PubMed] 
8. Keokilwe, L.; Olivier, A.; Burger, W.P.; Joubert, H.; Venter, E.H.; Morar-Leather, D. Bacterial enteritis in ostrich (Struthio Camelus) chicks in the Western Cape Province, South Africa. Poult. Sci. 2015, 94, 1177-1183. [CrossRef] [PubMed]

9. Kim, H.Y.; Byun, J.W.; Roh, I.S.; Bae, Y.C.; Lee, M.H.; Kim, B.; Songer, J.G.; Jung, B.Y. First isolation of Clostridium perfringens type E from a goat with diarrhea. Anaerobe 2013, 22, 141-143. [CrossRef] [PubMed]

10. Redondo, L.M.; Farber, M.; Venzano, A.; Jost, B.H.; Parma, Y.R.; Fernandez-Miyakawa, M.E. Sudden death syndrome in adult cows associated with Clostridium perfringens type E. Anaerobe 2013, 20,1-4. [CrossRef] [PubMed]

11. Songer, J.G. Clostridial enteric diseases of domestic animals. Clin. Microbiol. Rev. 1996, 9, 216-234. [CrossRef] [PubMed]

12. Ferrarezi, M.C.; Cardoso, T.C.; Dutra, I.S. Genotyping of Clostridium perfringens isolated from calves with neonatal diarrhea. Anaerobe 2008, 14, 328-331. [CrossRef] [PubMed]

13. Billington, S.J.; Wieckowski, E.U.; Sarker, M.R.; Bueschel, D.; Songer, J.G.; McClane, B.A. Clostridium perfringens type $\mathrm{E}$ animal enteritis isolates with highly conserved, silent enterotoxin gene sequences. Infect. Immun. 1998, 66, 4531-4536. [PubMed]

14. Popoff, M.R. Detection of toxigenic Clostridia. In PCR Detection of Microbial Pathogens; Sachse, K., Frey, J., Eds.; Humana Press: Totowa, NJ, USA, 2002; Volume 216, pp. 137-152.

15. Irikura, D.; Monma, C.; Suzuki, Y.; Nakama, A.; Kai, A.; Fukui-Miyazaki, A.; Horiguchi, Y.; Yoshinari, T.; Sugita-Konishi, Y.; Kamata, Y. Identification and Characterization of a New Enterotoxin Produced by Clostridium perfringens Isolated from Food Poisoning Outbreaks. PLoS ONE 2015, 10, e0138183. [CrossRef] [PubMed]

16. Yonogi, S.; Matsuda, S.; Kawai, T.; Yoda, T.; Harada, T.; Kumeda, Y.; Gotoh, K.; Hiyoshi, H.; Nakamura, S.; Kodama, T.; et al. BEC, a novel enterotoxin of Clostridium perfringens found in human clinical isolates from acute gastroenteritis outbreaks. Infect. Immun. 2014, 82, 2390-2399. [CrossRef] [PubMed]

17. Li, J.; Miyamoto, K.; McClane, B.A. Comparison of virulence plasmids among Clostridium perfringens type $\mathrm{E}$ isolates. Infect. Immun. 2007, 75, 1811-1819. [CrossRef] [PubMed]

18. Miyamoto, K.; Yumine, N.; Mimura, K.; Nagahama, M.; Li, J.; McClane, B.A.; Akimoto, S. Identification of novel Clostridium perfringens type $\mathrm{E}$ strains that carry an iota toxin plasmid with a functional enterotoxin gene. PLoS ONE 2011, 6, e20376. [CrossRef] [PubMed]

19. Perelle, S.; Gibert, M.; Boquet, P.; Popoff, M.R. Characterization of Clostridium perfringens iota-toxin genes and expression in Escherichia coli. Infect. Immun. 1993, 61, 5147-5156. [PubMed]

20. Toniti, W.; Yoshida, T.; Tsurumura, T.; Irikura, D.; Monma, C.; Kamata, Y.; Tsuge, H. Crystal structure and structure-based mutagenesis of actin-specific ADP-ribosylating toxin CPILE-a as novel enterotoxin. PLoS ONE 2017, 12, e0171278. [CrossRef] [PubMed]

21. Deguchi, A.; Miyamoto, K.; Kuwahara, T.; Miki, Y.; Kaneko, I.; Li, J.; McClane, B.A.; Akimoto, S. Genetic characterization of type A enterotoxigenic Clostridium perfringens strains. PLoS ONE 2009, 4, e5598. [CrossRef] [PubMed]

22. Xiao, Y.; Wagendorp, A.; Moezelaar, R.; Abee, T.; Wells-Bennik, M.H. A wide variety of Clostridium perfringens type A food-borne isolates that carry a chromosomal cpe gene belong to one multilocus sequence typing cluster. Appl. Environ. Microbiol. 2012, 78, 7060-7068. [CrossRef] [PubMed]

23. Gibert, M.; Petit, L.; Raffestin, S.; Okabe, A.; Popoff, M.R. Clostridium perfringens iota-toxin requires activation of both binding and enzymatic components for cytopathic activity. Infect. Immun. 2000, 68, 3848-3853. [CrossRef] [PubMed]

24. Bradford, M.M. A rapid and sensitive method for the quantitation of microgram quantities of protein utilizing the principle of protein-dye binding. Anal Biochem. 1976, 72, 248-254. [CrossRef]

25. Popoff, M.R.; Milward, F.W.; Bancillon, B.; Boquet, P. Purification of the Clostridium spiroforme binary toxin and activity of the toxin on HEp-2 cells. Infect. Immun. 1989, 57, 2462-2469. [PubMed]

26. Perelle, S.; Scalzo, S.; Kochi, S.; Mock, M.; Popoff, M.R. Immunological and functional comparison between Clostridium perfringens iota toxin, C. spiroforme toxin, and anthrax toxins. FEMS Microbiol. Lett. 1997, 146, 117-121. [CrossRef] [PubMed]

27. Mazuet, C.; Legeay, C.; Sautereau, J.; Ma, L.; Bouchier, C.; Bouvet, P.; Popoff, M.R. Diversity of Group I and II Clostridium botulinum strains from France including recently Identified subtypes. Genome Biol. Evol. 2016, 8, 1643-1660. [CrossRef] [PubMed] 
28. Bankevich, A.; Nurk, S.; Antipov, D.; Gurevich, A.A.; Dvorkin, M.; Kulikov, A.S.; Lesin, V.M.; Nikolenko, S.I.; Pham, S.; Prjibelski, A.D.; et al. SPAdes: A New genome assembly algorithm and its applications to single-cell sequencing. J. Comput. Biol. 2012, 19, 455-477. [CrossRef] [PubMed]

29. Seeman, T. Prokka: Rapid prokaryotic genome annotation. Bioinformatics 2014, 30, 2068-2069. [CrossRef] [PubMed]

30. Galardini, M.; Biondi, E.G.; Bazzicalupo, M.; Mengoni, A. CONTIGuator: A bacterial genomes finishing tool for structural insights on draft genomes. Source Code Biol. Med. 2011, 6, 11. [CrossRef] [PubMed]

31. Shimizu, T.; Ohtani, K.; Hirakawa, H.; Ohshima, K.; Yamashita, A.; Shiba, T.; Ogasawara, N.; Hattori, M.; Kuhara, S.; Hayashi, H. Complete genome sequence of Clostridium perfringens, an anaerobic flesh-eater. Proc. Natl. Acad. Sci. USA 2002, 99, 996-1001. [CrossRef] [PubMed]

32. Treangen, T.J.; Ondov, B.D.; Koren, S.; Phillippy, A.M. The Harvest suite for rapid core-genome alignment and visualization of thousands of intraspecific microbial genomes. Genome Biol. 2014, 15, 524. [CrossRef] [PubMed]

33. Nguyen, L.T.; Schmidt, H.A.; von Haeseler, A.; Minh, B.Q. IQ-TREE: A Fast and Effective Stochastic Algorithm for Estimating Maximum-Likelihood Phylogenies. Mol. Biol. Evol. 2015, 32, 268-274. [CrossRef] [PubMed]

(C) 2019 by the authors. Licensee MDPI, Basel, Switzerland. This article is an open access article distributed under the terms and conditions of the Creative Commons Attribution (CC BY) license (http:/ / creativecommons.org/licenses/by/4.0/). 